\title{
PEDAGOGIA DECOLONIAL E EDUCAÇÃO ANTIRRACISTA E INTERCULTURAL NO BRASIL
}

\author{
Luiz Fernandes de Oliveira* \\ Vera Maria Ferrão Candau**
}

RESUMO: O texto situa-se no âmbito da pesquisa "Multiculturalismo, Direitos Humanos e Educação: a tensão entre igualdade e diferença", que vem sendo desenvolvida desde 2006, tendo como um de seus principais objetivos analisar a problemática da educação intercultural no contexto latino-americano. No percurso investigativo realizado, foi privilegiada a produção do grupo Modernidade-Colonialidade, por seu potencial crítico para a discussão das relações entre interculturalidade, relações étnico-raciais e educação no Brasil. Em primeiro lugar, é feita uma breve análise dos principais conceitos que fundamentam as reflexões desse grupo. Em seguida, são apresentadas as noções de pedagogia decolonial e interculturalidade crítica. Por último, são discutidas possíveis confluências entre as propostas da pedagogia decolonial e intercultural e as das "Diretrizes Curriculares Nacionais para a Educação das Relações ÉtnicoRaciais e para o Ensino de História e Cultura Afro-Brasileira e Africana".

Palavras-chave: Modernidade/Colonialidade; Pedagogia Decolonial; Educação Intercultural.

\section{DECOLONIAL PEDAGOGY AND ANTI-RACIST AND INTERCULTURAL EDUCATION IN BRAZIL}

ABSTRACT: This text falls within the scope of the research field known as "Multiculturalism, Human Rights and Education: the tension between equality and difference", which has been developed since 2006, having as one of its objectives the study of issues related to intercultural education in Latin America. In the research process, special emphasis was given to the production of the "Modernity/Coloniality" working group for its critical potential in the discussion of the relationship between interculturality, ethnic-racial relations and education in Brazil. Firstly, a brief analysis of the main concepts, which are the basis of their work, is carried out. Then, the notion of decolonial pedagogy and critical interculturality is presented. Finally, the possible intersections between the propositions of decolonial and intercultural pedagogy and the National Curriculum Guidelines for the education of Ethnic-racial relations and for the teaching of Afro-Brazilian and African History and Culture are discussed.

Keywords: Modernity/coloniality; Decolonial pedagogy; Intercultural education.

\footnotetext{
* Doutorando do Programa de Pós-Graduação em Educação da Pontifícia Universidade Católica do Rio de Janeiro (PUC-Rio); Mestre em Sociologia pela Universidade do Estado do Rio de Janeiro (UERJ); Especialista em História da África e do Negro no Brasil pela Universidade Cândido Mendes (UCAM); Professor Assistente da Universidade do Estado do Rio de Janeiro (UERJ); Professor de Sociologia da Fundação de Apoio à Escola Técnica do Estado do Rio de Janeiro (FAETEC). Membro do Grupo de Pesquisa sobre Cotidiano, Educação e Cultura(s) (GECEC; PUC-Rio.).E-mail: axelui@@uol.com.br

* * Doutora em Educação pela Universidad Complutense de Madrid; Professora Titular do Departamento de Educação da Pontifícia Universidade Católica do Rio de Janeiro (PUC-Rio); Pesquisadora do Conselho Nacional de Desenvolvimento Científico e Tecnológico (CNPq); Coordenadora do Grupo de Pesquisas sobre Cotidiano, Educação e Cultura(s) (GECEC - PUC-Rio). Membro do Comitê Nacional de Educação em Direitos Humanos. E-mail: vmf@@puc-rio.br
} 


\section{Introdução}

Nos últimos anos, a problemática das relações entre educação e diferenças culturais tem sido objeto de inúmeros debates, reflexões e pesquisas, no Brasil e em todo o continente latino-americano. As questões e os desafios se multiplicam. As buscas de construção de processos educativos culturalmente referenciados se intensificam.

Nesse universo de preocupações, os estudos sobre relações étnico-raciais vêm se projetando no espaço acadêmico e nos movimentos sociais, a ponto de interferir de forma concreta em políticas públicas e ações governamentais. De fato, essa constatação pode ser melhor compreendida a partir do crescimento das lutas dos movimentos negros e da emergência de novas produções acadêmicas sobre questões relativas à diferença étnica, ao multiculturalismo e às identidades culturais.

Situando-nos nessa perspectiva, vimos desenvolvendo, desde 2006, um projeto de pesquisa1 intitulado "Multiculturalismo, Direitos Humanos e Educação: a tensão entre igualdade e diferença", orientado a aprofundar a discussão sobre a problemática da educação intercultural em diferentes países latino-americanos, por considerá-la um espaço privilegiado para se refletir sobre a tensão entre igualdade e diferença.

Nesse contexto, localizamos a produção do grupo "Modernidade/ Colonialidade", formado por intelectuais de diferentes procedências e inserções, que busca construir um projeto epistemológico, ético e político a partir de uma crítica à modernidade ocidental em seus postulados históricos, sociológicos e filosóficos. Consideramos as contribuições desse grupo de especial relevância e originalidade, apresentando potencial instigante para a reflexão sobre interculturalidade, relações étnico-raciais e educação, no contexto atual do continente latino-americano e, especificamente, no nosso país.

É a partir dessas observações preliminares que situamos o presente trabalho, que tem por objetivo analisar as principais contribuições do grupo "Modernidade-Colonialidade" para as discussões sobre as questões étnico-raciais no campo da educação no Brasil.

Em primeiro lugar, faremos uma breve análise das ideias e principais formulações teóricas desse grupo. Em seguida, situaremos o desenvolvimento de processos educacionais da educação a partir das noções de pedagogia decolonial e interculturalidade crítica. Num terceiro 
e último momento, entraremos nos debates sobre as questões raciais em educação no Brasil, analisando as possíveis confluências entre as propostas da pedagogia decolonial e intercultural e as políticas públicas de reformulação curricular no Brasil, tendo como referência as Diretrizes Curriculares Nacionais para a Educação das Relações Étnico-Raciais e para o Ensino de História e Cultura Afro-Brasileira e Africana².

\section{0 grupo "Modernidade/Colonialidade": referências fundamentais}

Em julho de 2002, Arturo Escobar, antropólogo colombiano e professor da Universidade da Carolina do Norte, apresentou um trabalho no terceiro Congresso Internacional de Latinoamericanistas, em Amsterdã, intitulado "Mundos e conhecimentos de outro modo", no qual fazia referência ao grupo de pesquisa "Modernidade/Colonialidade". O trabalho apresentado analisava e relatava a perspectiva de um grupo que busca um mundo melhor e um projeto epistemológico novo. Trata-se, em síntese, de uma construção alternativa à modernidade eurocêntrica, tanto no seu projeto de civilização quanto em suas propostas epistêmicas.

O grupo é formado predominantemente por intelectuais da América Latina e apresenta caráter heterogêneo e transdisciplinar. As figuras centrais desse grupo são: o filósofo argentino Enrique Dussel, o sociólogo peruano Aníbal Quijano, o semiólogo e teórico cultural argentino-norte-americano Walter Mignolo, o sociólogo porto-riquenho Ramón Grosfoguel, a linguista norte-americana radicada no Equador Catherine Walsh, o filósofo porto-riquenho Nelson Maldonado Torres, o antropólogo colombiano Arturo Escobar, entre outros. Cabe ressaltar que esse grupo mantém diálogos e atividades acadêmicas conjuntas com o sociólogo norte-americano Immanuel Wallerstein.

O postulado principal do grupo é o seguinte: "a colonialidade é constitutiva da modernidade, e não derivada” (MIGNOLO, 2005, p. 75). Ou seja, modernidade e colonialidade são as duas faces da mesma moeda. Graças à colonialidade, a Europa pode produzir as ciências humanas como modelo único, universal e objetivo na produção de conhecimentos, além de deserdar todas as epistemologias da periferia do ocidente. 
Segundo Quijano (2007), colonialismo e colonialidade são dois conceitos relacionados, porém distintos. O colonialismo se refere a um padrão de dominação e exploração no qual:

O controle da autoridade política, dos recursos de produção e do trabalho de uma população determinada possui uma diferente identidade e as suas sedes centrais estão, além disso, em outra jurisdição territorial. Porém nem sempre, nem necessariamente, implica relações racistas de poder. O Colonialismo é, obviamente, mais antigo; no entanto a colonialidade provou ser, nos últimos 500 anos, mais profunda e duradoura que o colonialismo. Porém, sem dúvida, foi forjada dentro deste, e mais ainda, sem ele não teria podido ser imposta à inter-subjetividade de modo tão enraizado e prolongado. (QUIJANO, 2007, p. 93)

Também Nelson Maldonado Torres (2007), de forma que consideramos mais esclarecedora, diferenciou os dois conceitos da seguinte forma:

O colonialismo denota uma relação política e econômica, na qual a soberania de um povo está no poder de outro povo ou nação, o que constitui a referida nação em um império. Diferente desta idéia, a colonialidade se refere a um padrão de poder que emergiu como resultado do colonialismo moderno, mas em vez de estar limitado a uma relação formal de poder entre dois povos ou nações, se relaciona à forma como o trabalho, o conhecimento, a autoridade e as relações intersubjetivas se articulam entre si através do mercado capitalista mundial e da idéia de raça. Assim, apesar do colonialismo preceder a colonialidade, a colonialidade sobrevive ao colonialismo. Ela se mantém viva em textos didáticos, nos critérios para o bom trabalho acadêmico, na cultura, no sentido comum, na auto-imagem dos povos, nas aspirações dos sujeitos e em muitos outros aspectos de nossa experiência moderna. Neste sentido, respiramos a colonialidade na modernidade cotidianamente. (TORRES, 2007, p. 131).

Assim, o colonialismo é mais do que uma imposição política, militar, jurídica ou administrativa. $\mathrm{Na}$ forma da colonialidade, ele chega às raízes mais profundas de um povo e sobrevive apesar da descolonização ou da emancipação das colônias latino-americanas, asiáticas e africanas nos séculos XIX e XX. O que esses autores mostram é que, apesar do fim dos colonialismos modernos, a colonialidade sobrevive.

É preciso lembrar que, com a emancipação jurídico-política da África e da Ásia, processos que culminam nos anos 1970, foram produ- 
zidas densas e consistentes reflexões sobre uma época denominada póscolonial (BHABHA, 1999; SAID, 2001; HALL, 1997; entre outros), indicando que o colonialismo teria terminado. Apesar de o colonialismo tradicional ter chegado ao fim, para os autores do grupo "Modernidade/ Colonialidade" as estruturas subjetivas, os imaginários e a colonização epistemológica ainda estão fortemente presentes.

Quijano (2005) vai propor o conceito de colonialidade do poder para referir-se a essa situação. Esta seria uma estrutura de dominação que submeteu a América Latina, a África e a Ásia, a partir da conquista. O termo faz alusão à invasão do imaginário do outro, ou seja, sua ocidentalização. Mais especificamente, diz respeito a um discurso que se insere no mundo do colonizado, porém também se reproduz no lócus do colonizador. Nesse sentido, o colonizador destrói o imaginário do outro, invizibilizando-o e subalternizando-o, enquanto reafirma o próprio imaginário. Assim, a colonialidade do poder reprime os modos de produção de conhecimento, os saberes, o mundo simbólico, as imagens do colonizado e impõe novos. Operase, então, a naturalização do imaginário do invasor europeu, a subalternização epistêmica do outro não-europeu e a própria negação e o esquecimento de processos históricos não-europeus. Essa operação se realizou de várias formas, como a sedução pela cultura colonialista, o fetichismo cultural que o europeu cria em torno de sua cultura, estimulando forte aspiração à cultura europeia por parte dos sujeitos subalternizados. Portanto, o eurocentrismo não é a perspectiva cognitiva somente dos europeus, mas torna-se também do conjunto daqueles educados sob sua hegemonia.

Nesse sentido, pode-se afirmar que a colonialidade do poder construiu a subjetividade do subalternizado, necessitando, portanto, segundo Quijano (2007), pensar historicamente a noção de raça.

A colonialidade é um dos elementos constitutivos e específicos do padrão mundial do poder capitalista. Se funda na imposição de uma classificação racial/étnica da população mundial como pedra angular deste padrão de poder (QUIJANO, 2007, p. 93).

Quijano explicita que o conceito de raça é uma abstração, uma invenção que nada tem a ver com processos biológicos. É no século XVI que se cria a união entre cor e raça, e, mais, esse conceito, para o autor, exerce papel fundamental no desenvolvimento do capitalismo moderno a partir do século XIX. 
Além disso, esse conceito operou a inferiorização de grupos humanos não-europeus, do ponto de vista da produção da divisão racial do trabalho, do salário, da produção cultural e dos conhecimentos. Por isso, Quijano fala também da colonialidade do saber, entendida como a repressão de outras formas de produção de conhecimento não-europeias, que nega o legado intelectual e histórico de povos indígenas e africanos, reduzindo-os, por sua vez, à categoria de primitivos e irracionais, pois pertencem a "outra raça".

Essa afirmação da hegemonia epistemológica da modernidade europeia, que se traduz num racismo epistêmico ou, como afirma Grosfoguel (2007), sobre como a "epistemologia eurocêntrica ocidental dominante, não admite nenhuma outra epistemologia como espaço de produção de pensamento crítico nem científico" (GROSFOGUEL, 2007, p. 35).

Walter Mignolo (2005), nessa linha de raciocínio, vai afirmar que as ciências humanas, legitimadas pelo Estado, cumpriram papel fundamental na invenção do outro. Além disso, segundo esse mesmo autor, essas ciências, incluindo a história, criaram a noção de progresso. Com a ideia de progresso se estabeleceu uma linha temporal em que a Europa aparecia como superior. Isso significou que, como afirma CastroGomez (2005) sobre a história e as áreas afins, como a etnografia, a geografia, a antropologia, a paleontologia, a arqueologia, etc., ao estudar o passado das civilizações, seus produtos culturais e institucionais, muitas vezes foram realizadas comparações com o mundo europeu e, nesse sentido, justificaram o colonialismo ${ }^{3}$. Para esse autor, os cânones, o modelo, o padrão de comparação, são o "centro" da História Mundial, ou seja, a Europa. Aqui, o outro foi visto como mera natureza, uma visão que se popularizou no século XVIII e que teve suas repercussões na obra de Hegel sobre a Filosofia da História ${ }^{4}$.

Mignolo (2003) escreve que os espanhois julgavam e hierarquizavam a inteligência e a civilização dos povos tomando como critério a escrita alfabética. Porém, nos séculos XVIII e XIX, o critério de avaliação passa a ser a história. Ou seja, os povos "sem história" situam-se em um tempo "anterior" ao "presente".

Assim, com base na colonialidade do poder:

(...) o eurocentrismo torna-se, portanto, uma metáfora para descrever a colonialidade do poder, na perspectiva da subalternidade. Da perspectiva epistemológica, o saber e as histórias locais européias foram vistos como 
projetos globais, desde o sonho de um Orbis universalis christianus até a crença de Hegel em uma história universal, narrada de uma perspectiva que situa a Europa como ponto de referência e de chegada. (MIGNOLO, 2003, p. 41)

Para Mignolo, a expansão ocidental após o século XVI não foi somente econômica e religiosa, mas também das formas hegemônicas de conhecimento, de um conceito de representação do conhecimento e cognição, impondo-se como hegemonia epistêmica, política e historiográfica, estabelecendo, assim, a colonialidade do saber.

Se a colonialidade do poder criou uma espécie de fetichismo epistêmico (ou seja, a cultura, as ideias e os conhecimentos dos colonialistas aparecem de forma sedutora, que se busca imitar), impondo a colonialidade do saber sobre os não-europeus, evidenciou-se também uma geopolítica do conhecimento, ou seja, o poder, o saber e todas as dimensões da cultura definiam-se a partir de uma lógica de pensamento localizado na Europa. Assim, Mignolo (2005) também vai afirmar que esses processos, marcados por uma violência epistêmica, conduziram também a uma geopolítica linguística, já que as línguas coloniais ou imperiais, cronologicamente identificadas no grego e no latim na Antiguidade, e no italiano, no português, no castelhano, no francês, no inglês e no alemão na modernidade, estabeleceram o monopólio linguístico, desprezando as línguas nativas e, como consequência, subvertendo ideias, imaginários e as próprias cosmovisões nativas fora da Europa.

Entretanto, é no conceito de colonialidade do ser, segundo os vários autores aqui expostos, que mais se explicita a força dos conceitos vistos anteriormente. Catherine Walsh (2005) vai recordar as palavras de Frantz Fanon (1983) para relacionar colonialismo a não-existência:

Em virtude de ser uma negação sistemática da outra pessoa e uma determinação furiosa para negar ao outro todos os atributos de humanidade, o colonialismo obriga as pessoas que ele domina a perguntar-se: em realidade quem eu sou? (FANON apud WALSH, 2005, p. 22).

E mais:

O mundo colonial é um mundo maniqueísta. Não basta ao colonizador limitar fisicamente o colonizado, com suas polícias e seus exércitos, o espaço do colonizado. Assim, para ilustrar o caráter totalitário da exploração colonial, o colonizador faz do colonizado uma quinta-essência do mal. A sociedade 
colonizada não somente se define como uma sociedade sem valores (...) O indígena é declarado impermeável à ética, aos valores. É, e nos atrevemos a dizer, o inimigo dos valores. Neste sentido, ele é um mal absoluto. Elemento corrosivo de tudo o que o cerca, elemento deformador, capaz de desfigurar tudo que se refere à estética ou à moral, depositário de forças maléficas. (FANON, 2003, p. 35-36).

A colonialidade do ser é pensada, portanto, como a negação de um estatuto humano para africanos e indígenas, por exemplo, na história da modernidade colonial. Essa negação, segundo Walsh (2006), implanta problemas reais em torno da liberdade, do ser e da história do indivíduo subalternizado por uma violência epistêmica.

Podemos afirmar, concordando com Mignolo (2003), que o discurso da história do pensamento europeu é, de um lado, a história da modernidade europeia e, de outro, a história silenciada da colonialidade europeia. Pois, enquanto a primeira é uma história de autoafirmação e de celebração dos sucessos intelectuais e epistêmicos, a segunda é uma história de negações e de rejeição de outras formas de racionalidade e história.

\section{Colonialidade e educação}

A partir desses conceitos fundamentais, desde o final dos anos 1990, o grupo vem se ampliando e afirmando suas reflexões sobre as relações entre colonialidade e modernidade. Segundo Catherine Walsh, a partir de 2001, com o convênio entre a Universidade Duke, a Universidade da Carolina do Norte, a Universidade Javeriana de Bogotá e a Universidade Andina Simon Bolívar de Quito, com a participação de intelectuais da Bolívia, da Colômbia, do Peru, do Equador, da Venezuela, da Argentina, do México e dos EUA, estabeleceu-se um intenso diálogo que influenciou as grandes questões abordadas pelo primeiro Programa de Doutorado em Estudos Culturais Latinoamericanos da Universidade Andina Simon Bolívar do Equador (WALSH, 2005). Em outubro de 2007, realizamos um seminário presencial, no Rio de Janeiro, com a professora Catherine Walsh, em que discutimos e aprofundamos a perspectiva desenvolvida pelo grupo "Modernidade/Colonialidade", especialmente em suas relações com a educação. 
A questão central num projeto de emancipação epistêmica é a coexistência de diferentes epistêmes ou formas de produção de conhecimento entre intelectuais, tanto na academia, quanto nos movimentos sociais, colocando em evidência a questão da geopolítica do conhecimento. Como visto anteriormente, entende-se geopolítica do conhecimento como a estratégia da modernidade europeia que afirmou suas teorias, seus conhecimentos e seus paradigmas como verdades universais e invisibilizou e silenciou os sujeitos que produzem conhecimentos "outros". Foi esse o processo que constituiu a modernidade que não pode ser entendida sem se tomar em conta os nexos com a herança colonial e as diferenças étnicas que o poder moderno/colonial produziu.

Segundo Arturo Escobar (2003), a modernidade como globalização atualmente está em todas as partes, já que esta é a radicalização e a universalização da modernidade europeia em todos os cantos do planeta. Porém, hoje emerge uma série de noções que colocam em crise a centralidade da perspectiva eurocêntrica. Por exemplo, a perspectiva de que a modernidade não é um fenômeno europeu, mas um fenômeno global, com distintas localidades e temporalidades.

Essa perspectiva considera a colonialidade como constitutiva da modernidade, ou seja, segundo Mignolo (2003), "nos ombros da modernidade está o peso e a responsabilidade da colonialidade" (MIGNOLO, 2003, p. 38). Daí surge a perspectiva de introduzir epistêmes invisibilizadas e subalternizadas, fazendo-se a crítica ao mesmo tempo da colonialidade do poder.

Como vimos, a colonialidade do poder, do saber e do ser são conceitos centrais dentro do projeto de investigação do grupo "Modernidade/Colonialidade". Outro conceito central, introduzido por Mignolo, é a diferença colonial, entendida como pensar a partir das ruínas, das experiências e das margens criadas pela colonialidade do poder na estruturação do mundo moderno/colonial, como forma não de restituir conhecimento, mas de reconhecer conhecimentos "outros" em um horizonte epistemológico transmoderno, ou seja, construído a partir de formas de ser, pensar e conhecer diferentes da modernidade europeia, porém em diálogo com esta.

A perspectiva da diferença colonial requer um olhar sobre enfoques epistemológicos e sobre as subjetividades subalternizadas e excluídas. Supõe interesse por produções de conhecimento distintas da 
modernidade ocidental. Diferentemente da pós-modernidade, que continua pensando tendo como referência o ocidente moderno, a construção de um pensamento crítico "outro", parte das experiências e histórias marcadas pela colonialidade. O eixo que se busca é a conexão de formas críticas de pensamento produzidas a partir da América Latina, assim como com autores de outros lugares do mundo, na perspectiva da decolonialidade da existência, do conhecimento e do poder.

Assim, neste enfoque crítico, Catherine Walsh vai refletir sobre os processos educacionais a partir de conceitos como: pensamento-outro, decolonialidade e pensamento crítico de fronteira.

Pensamento-outro provém do autor árabe-islâmico Abdelkebir Khatibi, que parte do princípio da possibilidade do pensamento a partir da decolonização, ou seja, a luta contra a não-existência, a existência dominada e a desumanização. É uma perspectiva semelhante à proposta pelo conceito de colonialidade do ser, uma categoria que serve como força para questionar a negação histórica da existência dos não-europeus, como os afrodescendentes e indígenas da América Latina.

Contestando as concepções de que diversos povos nãoocidentais seriam não-modernos, atrasados e não-civilizados, decolonizarse cumpre papel fundamental do ponto de vista epistemológico e político.

Walsh afirma, tendo como referência os movimentos sociais indígenas equatorianos e dos afro-equatorianos, que a decolonialidade implica partir da desumanização e considerar as lutas dos povos historicamente subalternizados pela existência, para a construção de outros modos de viver, de poder e de saber. Portanto, decolonialidade é visibilizar as lutas contra a colonialidade a partir das pessoas, das suas práticas sociais, epistêmicas e políticas.

A decolonialidade representa uma estratégia que vai além da transformação da descolonização, ou seja, supõe também construção e criação. Sua meta é a reconstrução radical do ser, do poder e do saber.

Walter Mignolo (2003) destaca que o pensamento-outro caracterizado como decolonialidade se expressa na diferença colonial, isto é, um reordenamento da geopolítica do conhecimento em duas direções: a crítica da subalternização na perspectiva dos conhecimentos invisibilizados e a emergência do pensamento liminar como uma nova modalidade epistemológica na interseção da tradição ocidental e a diversidade de categorias suprimidas sob o ocidentalismo e o eurocentrismo. 
Mignolo (2003) cita um exemplo quando descreve o marxismo modificado pelas línguas e pela cosmologia ameríndia do movimento zapatista e a epistemologia ameríndia transformada pela linguagem do marxismo, ou seja, um diálogo trans-epistemológico que reescreve uma história de quinhentos anos de opressão.

Outro exemplo citado pelo autor é quando Fanon, no livro Peles negras e máscaras brancas, afirma que para um negro que trabalha numa plantação de açúcar a única solução é lutar, mas que ele "embarcará nessa luta, e a levará adiante, não como resultado de uma análise marxista ou idealista, mas simplesmente porque não pode conceber a vida de outra maneira" (FANON apud MIGNOLO, 2003, p. 126).

Mignolo quer destacar aqui que Fanon "não está negando a poderosa análise da lógica do capitalismo efetuada por Marx", mas está "chamando a atenção para a força da consciência negra, e não apenas da consciência de classe" (MIGNOLO, 2003, p. 126).

Nesse processo, também se encontra a estratégia da interculturalidade como princípio que orienta pensamentos, ações e novos enfoques epistêmicos. O conceito de interculturalidade é central na (re)construção do pensamento-outro. A interculturalidade é concebida, nessa perspectiva, como processo e como projeto político.

Amadurecendo esse pensamento, Walsh (2005) considera também a questão do "posicionamento crítico de fronteira" na diferença colonial, ou seja, um processo em que o fim não é uma sociedade ideal, como abstrato universal, mas o questionamento e a transformação da colonialidade do poder, do saber e do ser, sempre tendo consciência de que estas relações de poder não desaparecem, mas que podem ser reconstruídas ou transformadas, conformando-se de outra maneira.

O pensamento de fronteira significa tornar visíveis outras lógicas e formas de pensar, diferentes da lógica eurocêntrica dominante. $\mathrm{O}$ pensamento de fronteira se preocupa com o pensamento dominante, mantendo-o como referência, como vimos em Fanon, mas sujeitando-o ao constante questionamento e introduzindo nele outras histórias e modos de pensar. Walsh considera essa perspectiva como componente de um projeto intercultural e decolonizador, permitindo uma nova relação entre conhecimento útil e necessário na luta pela decolonização epistêmica.

Além disso, o pensamento crítico de fronteira permite construir variadas estratégias entre grupos e conhecimentos subalternos, como, por 
exemplo, entre povos indígenas e povos negros. A autora coloca também, como exemplo, o estabelecimento de lugares epistêmicos do pensamentooutro, como a Universidade Intercultural Indígena do Equador ou a etnoeducação afro (WALSH, 2006). Esses espaços, como posições críticas de fronteira, podem oferecer possibilidades de propor outros conhecimentos e cosmovisões num diálogo crítico com os conhecimentos e modos de pensar tipicamente associados ao mundo ocidental.

Esse pensamento crítico pode se constituir desde a colonialidade e propõe que se crie novas comunidades interpretativas que ajudem a ver o mundo de uma perspectiva "outra". Esse enfoque quer se constituir como um projeto alternativo ao racismo epistêmico e à colonialidade do ser, do saber e do poder. Walsh (2007) afirma que a denominada pedagogia decolonial poderia servir no campo educativo para aprofundar os debates em torno da interculturalidade, ou seja,

ao problema da" ciência" em si; isto é, a maneira através da qual a ciência, como um dos fundamentos centrais do projeto Modernidade/Colonialidade, contribuiu de forma vital ao estabelecimento e manutenção da ordem hierárquica racial, histórica e atual, na qual os brancos e especialmente os homens brancos europeus permanecem como superiores. (WALSH, 2007, p. 9)

Aqui, faz-se necessário discutir um pouco mais sobre os conceitos de interculturalidade crítica e sua incidência no campo educacional e a pedagogia decolonial.

Para Catherine Walsh, a interculturalidade significa:

- Um processo dinâmico e permanente de relação, comunicação e aprendizagem entre culturas em condições de respeito, legitimidade mútua, simetria e igualdade.

- Um intercâmbio que se constrói entre pessoas, conhecimentos, saberes e práticas culturalmente diferentes, buscando desenvolver um novo sentido entre elas na sua diferença.

- Um espaço de negociação e de tradução onde as desigualdades sociais, econômicas e políticas, e as relações e os conflitos de poder da sociedade não são mantidos ocultos e sim reconhecidos e confrontados.

- Uma tarefa social e política que interpela ao conjunto da sociedade, que parte de práticas e ações sociais concretas e conscientes e tenta criar modos de responsabilidade e solidariedade.

- Uma meta a alcançar. (WALSH, 2001, p. 10-11) 
Outro estudo da autora destaca que:

O conceito de interculturalidade é central à (re)construção de um pensamento crítico-outro - um pensamento crítico de/desde outro modo -, precisamente por três razões principais: primeiro porque está vivido e pensado desde a experiência vivida da colonialidade [...]; segundo, porque reflete um pensamento não baseado nos legados eurocêntricos ou da modernidade e, em terceiro, porque tem sua origem no sul, dando assim uma volta à geopolítica dominante do conhecimento que tem tido seu centro no norte global. (WALSH, 2005, p. 25)

Para a autora, a interculturalidade tem um significado intimamente ligado a um projeto social, cultural, educacional, político, ético e epistêmico em direção à decolonização e à transformação. É um conceito carregado de sentido pelos movimentos sociais indígenas latinoamericanos e que questiona a colonialidade do poder, do saber e do ser. Enfim, ele também denota outras formas de pensar e se posicionar a partir da diferença colonial, na perspectiva de um mundo mais justo.

É nesse sentido que a interculturalidade não é compreendida somente como um conceito ou termo novo para referir-se ao simples contato entre o ocidente e outras civilizações, mas como algo inserido numa configuração conceitual que propõe um giro epistêmico capaz de produzir novos conhecimentos e outra compreensão simbólica do mundo, sem perder de vista a colonialidade do poder, do saber e do ser. A interculturalidade concebida nessa perspectiva representa a construção de um novo espaço epistemológico que inclui os conhecimentos subalternizados e os ocidentais, numa relação tensa, crítica e mais igualitária.

Segundo a autora, no campo educacional essa perspectiva não restringe a interculturalidade à mera inclusão de novos temas nos currículos ou nas metodologias pedagógicas, mas se situa na perspectiva da transformação estrutural e sócio-histórica. Aqui, portanto, a autora expressa uma crítica às formulações teóricas multiculturais que não questionam as bases ideológicas do Estado-nação, partem de lógicas epistêmicas eurocêntricas e, no campo educacional, sob o pretexto de incorporar representações e culturas marginalizadas, apenas reforçam os estereótipos e os processos coloniais de racialização.

Para Walsh, muitas políticas públicas educacionais na América Latina (incluindo o Brasil) vêm se utilizando dos termos interculturalidade 
e multiculturalismo como forma de somente incorporar as demandas e os discursos subalternizados pelo ocidente, dentro do aparato estatal em que o padrão epistemológico eurocêntrico e colonial continua hegemônico.

$\mathrm{Na}$ contramão dessa concepção meramente inclusiva, Walsh (2007) vai propor a perspectiva da interculturalidade crítica como a forma da pedagogia decolonial:

A interculturalidade crítica (...) é uma construção de e a partir das pessoas que sofreram uma experiência histórica de submissão e subalternização. Uma proposta e um projeto político que também poderia expandir-se e abarcar uma aliança com pessoas que também buscam construir alternativas à globalização neoliberal e à racionalidade ocidental, e que lutam tanto pela transformação social como pela criação de condições de poder, saber e ser muito diferentes. Pensada desta maneira, a interculturalidade crítica não é um processo ou projeto étnico, nem um projeto da diferença em si. (...), é um projeto de existência, de vida. (WALSH, 2007, p. 8)

Essa perspectiva é pensada a partir da ideia de uma prática política contraposta à geopolítica hegemônica monocultural e monorracional do conhecimento, pois se trata de visibilizar, enfrentar e transformar as estruturas e instituições que têm como horizonte de suas práticas e relações sociais a lógica epistêmica ocidental, a racialização do mundo e a manutenção da colonialidade do poder.

Assim afirma Walsh (2007, p. 9): “assumir esta tarefa implica um trabalho de-colonial dirigido a tirar as correntes e superar a escravização das mentes (como diziam Zapata Olivella y Malcolm X); a desafiar e derrubar as estruturas sociais, políticas e epistêmicas da colonialidade".

Portanto, a autora elabora, a partir dessa construção teórica, a noção de pedagogia decolonial, ou seja, uma práxis baseada numa insurgência educativa propositiva - portanto, não somente denunciativa em que o termo insurgir representa a criação e a construção de novas condições sociais, políticas, culturais e de pensamento. Em outros termos, a construção de uma noção e visão pedagógica que se projeta muito além dos processos de ensino e de transmissão de saber, que concebe a pedagogia como política cultural.

Walsh afirma que essa perspectiva ainda está em processo de construção, tanto do ponto de vista teórico quanto do da construção de práticas nos sistemas escolares e em outros âmbitos educativos. Cita como inspiração e referência para o seu desenvolvimento as formulações e 
práticas educacionais de Paulo Freire, além das teorizações de Frantz Fanon sobre a consciência do oprimido e a necessidade de humanização dos povos subalternizados.

No próximo item, discutiremos possíveis relações e aproximações entre as contribuições da pedagogia decolonial e intercultural, no contexto das questões raciais na educação brasileira atual.

\section{É possível desenvolver uma pedagogia decolonial, intercultural e antirracista na educação brasileira hoje?}

Para esta análise, propomo-nos ter como ponto de partida o ano de 1988, que, segundo Silva Jr. (2000), foi um marco para a redefinição do papel da África na concepção da nacionalidade brasileira. Nesse ano, foi assegurado, na Constituição - artigos 215 e 242 -, o reconhecimento da pluralidade étnica da sociedade brasileira e a garantia do ensino das contribuições das diferentes etnias na formação do povo brasileiro.

Tal reconhecimento de caráter jurídico atende a uma antiga reivindicação dos movimentos negros, que há anos sinalizavam a importância da inclusão da história dos negros nos currículos escolares, assim como o reconhecimento do caráter pluriétnico da nação brasileira. Essas discussões se intensificaram nos anos 1990, quando o conceito de afrodescendência ganha força enquanto fator de mobilização social e categoria histórica definidora de um pertencimento étnico. Ao mesmo tempo, nesse mesmo período, a categoria cultura, associada a categorias como identidade e etnia, passa a ser fundamental nas discussões no campo do currículo e da educação em geral.

Durante os anos pós-promulgação da Constituição, novos e velhos debates ocuparam o cenário acadêmico e social. Aprofundou-se a ruptura com o mito da democracia racial e avançou-se para as discussões no campo das ações afirmativas, com a polêmica acerca das cotas, principalmente raciais, nas universidades. Além disso, os chamados temas de interesse dos afrodescendentes adquirem maior visibilidade no universo das pesquisas acadêmicas em várias áreas do conhecimento.

Nas reformas educacionais dos anos 90, o Ministério de Educação elabora os Parâmetros Curriculares Nacionais (PCN), que, embora criticados por muitos docentes, incorporaram os chamados temas transversais, entre os quais o relativo à diversidade cultural. Em seguida à 
sua promulgação, as escolas e os professores receberam os PCNs, entre os quais o da área curricular de História, que destaca a importância social do conhecimento histórico e, a partir da análise da trajetória do ensino de história, critica a visão eurocêntrica que instituiu determinado modelo de identidade nacional. Apresenta ainda, como um de seus objetivos específicos, a construção da noção de identidade, relacionando identidades individuais, sociais e coletivas e propondo a apresentação de outros sujeitos históricos diferentes daqueles que dominaram o ensino dessa área curricular no Brasil.

É importante ressaltar também que o longo caminho de reivindicações dos movimentos negros relativos à área de educação dá origem à Lei n. 10.639 de 9 de janeiro de 2003, que afirma:

Art. 26-A Nos estabelecimentos de ensino fundamental e médio, oficiais e particulares, torna-se obrigatório o ensino sobre História e Cultura AfroBrasileira.

$\int 1^{\circ} \mathrm{O}$ conteúdo programático a que se refere o caput deste artigo incluirá o estudo da História da África e dos Africanos, a luta dos negros no Brasil, a cultura negra brasileira e o negro na formação da sociedade nacional, resgatando a contribuição do povo negro nas áreas social, econômica e política pertinente à História do Brasil.

$\int 2 \underline{\mathrm{O}}$ Os conteúdos referentes à História e Cultura Afro-Brasileira serão ministrados no âmbito de todo o currículo escolar, em especial nas áreas de Educação Artística e de Literatura e História Brasileira.

A lei provoca inicialmente intensa polêmica: para alguns significava imposição, para outros, uma concessão. Porém, com a realização de diversos fóruns estaduais e nacionais promovidos pelo Ministério da Educação e o empenho de diversos educadores e dos movimentos negros, os debates sobre o ensino da História da África e dos negros no Brasil nos currículos escolares vêm conquistando espaços como uma das formas de luta antirracista mais presente no contexto atual da sociedade brasileira.

Publicações começam a tomar corpo no cenário acadêmico, em revistas de divulgação científica e também na mídia. A iniciativa da Associação Nacional de Pós-Graduação e Pesquisa em Educação (Anped) de formação de um Grupo de Estudos Afro-brasileiros e Educação, a partir de 2002, a recorrência de artigos nas principais revistas acadêmicas de educação a partir de meados dos anos 90 e, principalmente, a fundação 
da Associação Brasileira de Pesquisadores Negros, em 2000, são realidades que se vêm afirmando nos últimos anos. Destaca-se também a ampliação, principalmente após a publicação da Lei 10.639/03, de cursos de especialização sobre História da África, relações étnico-raciais e educação em diversas universidades, assim como grupos de pesquisa e disciplinas vinculadas a diferentes programas de doutorado e mestrado que abordam questões vinculadas e essa temática.

Em 2005, é editado o projeto “A Cor da Cultura”, veiculado pela TV Futura, em parceria com o governo federal, que, através de programas educativos, contribuiu para divulgar ações e iniciativas de educadores, escolas e ONGs no campo das relações raciais e da educação, dando prioridade às metodologias pedagógicas para aplicação das diretrizes curriculares para a educação das relações étnico-raciais. Cabe destacar que esse projeto foi desenvolvido por uma equipe de profissionais selecionados junto aos movimentos sociais negros e a diversos especialistas ligados às principais universidades do país. Como vemos, se vêm desenvolvendo e afirmando redes envolvendo instituições acadêmicas, pesquisadores, educadores e movimentos sociais que há anos priorizam essas discussões.

No entanto, as polêmicas sobre as questões raciais e suas relações com a educação continuam fortemente presentes na sociedade e nos universos acadêmicos e pode-se afirmar que os debates incorporam inclusive certa geopolítica do conhecimento nas disputas sobre a noção de identidade nacional.

Quando a Lei 10.639/03 foi regulamentada, em junho de 2004, ela passou a representar mais um passo nas políticas de ações afirmativas e de reparação para a educação básica. Nos fundamentos teóricos da legislação, afirma-se que o racismo estrutural no Brasil explicita-se através de um sistema meritocrático, agrava desigualdades e gera injustiça. Destaca também que há uma demanda da comunidade afro-brasileira por reconhecimento, valorização e afirmação de direitos, no que diz respeito à educação, e que esse reconhecimento requer estratégias de valorização da diversidade. Além disso, esse reconhecimento passa pela ressignificação de termos como negro e raça, pela superação do etnocentrismo e das perspectivas eurocêntricas de interpretação da realidade brasileira e pela desconstrução de mentalidades e visões sobre a história da África e dos afro-brasileiros. 
As diretrizes formulam explicitamente uma perspectiva de políticas de reconhecimento da diferença nos aspectos políticos, culturais, sociais e históricos, mas também propõem, como obrigatórios, conteúdos pedagógicos nos sistemas de ensino, que, por sua vez, se caracterizam enquanto uma perspectiva nada tradicional na educação brasileira.

Nos debates em torno da Lei 10.639/03, podemos observar algumas semelhanças com as reflexões sobre a colonialidade do poder, do saber e do ser e a possibilidade de novas construções teóricas para a emergência da diferença colonial no Brasil e de uma proposta de interculturalidade crítica e de uma pedagogia decolonial.

Numa leitura atenta das novas Diretrizes Curriculares Nacionais para a Educação das Relações Étnico-Raciais e para o Ensino de História e Cultura Afro-Brasileira e Africana e do parecer 03 do Conselho Pleno do Conselho Nacional de Educação, de 10 de março de 2004, identificamos que, entre os objetivos, estão a garantia do igual direito às histórias e culturas que compõem a nação brasileira e a afirmação de que os conteúdos propostos devem conduzir à reeducação das relações étnico-raciais por meio da valorização da história e da cultura dos afrobrasileiros e dos africanos.

Essa demanda, destinada aos sistemas de ensino, escolas e professores, responde às reivindicações de políticas de ações afirmativas, reparações, reconhecimento e valorização de histórias, culturas e identidades dos movimentos sociais negros. Busca combater o racismo a partir do reconhecimento estatal e propõe a divulgação e a produção de conhecimentos que eduquem cidadãos orgulhosos de seu pertencimento étnico com direitos garantidos e identidades valorizadas.

Por outro lado, o termo reconhecimento implica: desconstruir o mito da democracia racial; adotar estratégias pedagógicas de valorização da diferença; reforçar a luta antirracista e questionar as relações étnicoraciais baseadas em preconceitos e comportamentos discriminatórios.

As diretrizes determinam também algumas condições para sua realização como: condições objetivas de trabalho para os profissionais da educação, reeducação das relações entre brancos e negros; ressignificação dos termos raça e etnia como categorias de análise e no sentido estritamente político, a superação do etnocentrismo eurocêntrico, a discussão do tema por toda a comunidade escolar e a perspectiva da interculturalidade em educação ou, como afirma o documento do CNE, 
"a educação das relações étnico-raciais impõe aprendizagens entre brancos e negros, trocas de conhecimentos, quebra de desconfianças, projeto conjunto para a construção de uma sociedade justa, igual, equânime" (BRASIL Parecer do CNE, 2004a, p. 6).

Essas orientações, segundo o texto do $\mathrm{CNE}$, constituem uma decisão política, com fortes repercussões pedagógicas e que dizem respeito a todos os cidadãos numa sociedade multicultural e pluriétnica. Trata-se de ampliar o foco dos currículos para o reconhecimento da diferença. Mais do que uma inclusão de determinadas temáticas, supõe repensar enfoques, relações e procedimentos em uma perspectiva nova.

Assim, as noções básicas que fundamentam o texto do CNE dizem respeito à igualdade entre os sujeitos de direitos e o reconhecimento dos grupos étnico-raciais. A nova legislação associa nação democrática com o reconhecimento de uma sociedade multicultural e pluriétnica, com o objetivo de educar na pluralidade para a interculturalidade e a valorização das identidades:

A Educação das Relações Étnico-Raciais tem por objetivo a divulgação e produção de conhecimentos, bem como de atitudes, posturas e valores que eduquem cidadãos quanto à pluralidade étnico-racial, tornando-os capazes de interagir e de negociar objetivos comuns que garantam a todos respeito aos direitos legais e valorização de identidade, na busca da consolidação da democracia brasileira. (Brasil, 2004b, p. 01)

O objetivo das Diretrizes é claro. Entretanto, uma questão se apresenta nas diversas experiências docentes (OLIVEIRA, 2007) e na literatura acadêmica: como aplicar um dispositivo legal, que traz uma fundamentação teórica e epistemológica não-eurocêntrica, numa realidade em que enfoques teóricos e epistemológicos eurocêntricos vêm tradicionalmente fundamentando a prática de ensino da maioria dos docentes?

Segundo Pereira (2007), por um lado, há uma disputa epistemológica quanto à interpretação da história e as perspectivas de análise social das relações raciais. Por outro, o campo do conhecimento histórico no Brasil vivencia profundas mudanças interpretativas que ainda não chegaram às salas de aula.

Nesse sentido, o impasse epistemológico é um dos mais evidentes, na medida em que os conteúdos propostos pelas diretrizes 
curriculares se encarregam de tentar construir uma nova interpretação da própria história em geral e do Brasil.

Para Moore (2007) as diretrizes Curriculares Nacionais estabelecem, por exemplo, algumas determinações de conteúdo no ensino de história que, além do fato de estarem ausentes nas formações inicias dos docentes, mobilizam uma reorientação epistemológica da interpretação da história:

Em História da África, tratada em perspectiva positiva, não só de denúncia da miséria e discriminações que atingem o continente, nos tópicos pertinentes se fará articuladamente com a história dos afrodescendentes no Brasil e serão abordados temas relativos: - ao papel dos anciãos e dos griots como guardiãos da memória histórica; - à história da ancestralidade e religiosidade africana; aos núbios e aos egípcios, como civilizações que contribuíram decisivamente para o desenvolvimento da humanidade; - às civilizações e organizações políticas pré-coloniais, como os reinos do Mali, do Congo e do Zimbabwe; ao tráfico e à escravidão do ponto de vista dos escravizados; - ao papel dos europeus, dos asiáticos e também de africanos no tráfico; - à ocupação colonial na perspectiva dos africanos; - às lutas pela independência política dos países africanos; - às ações em prol da união africana em nossos dias, bem como o papel da União Africana para tanto; - às relações entre as culturas e as histórias dos povos do continente africano e os da diáspora; - à formação compulsória da diáspora, vida e existência cultural e histórica dos africanos e seus descendentes fora da África; - à diversidade da diáspora, hoje, nas Américas, Caribe, Europa, Ásia; - aos acordos políticos, econômicos, educacionais e culturais entre África, Brasil e outros países da diáspora. (BRASIL, Parecer do CNE, 2004a, p. 12)

Segundo este mesmo autor (MOORE, 2007), contar a história da África é dar um estatuto epistemológico aos povos subalternizados e deslocar o foco de constituição e dinâmica da própria formação do ocidente europeu e da nação brasileira.

Essa desconstrução, ainda segundo o autor, pode gerar confusões e até uma reação conservadora, pois se trata de um profundo questionamento a uma interpretação histórica hegemônica que perpetrou uma "rejeição ontológica do outro" (MOORE, 2007).

Outro ponto, nesse aspecto, tem consequências na construção do conhecimento histórico, na medida em que se propõe:

O ensino de Cultura Africana abrangerá: - as contribuições do Egito para a ciência e filosofia ocidentais; - as universidades africanas Tambkotu, Gao, 
Djene que floresciam no século XVI; - as tecnologias de agricultura, de beneficiamento de cultivos, de mineração e de edificações trazidas pelos escravizados, bem como a produção científica, artística (artes plásticas, literatura, música, dança, teatro) política, na atualidade. (BRASIL, Parecer do CNE, 2004 , p. 12)

Ou seja, falar de contribuição científica e filosófica para o ocidente ou de tecnologias como a mineração, é de fato desconstruir, por exemplo, as bases epistemológicas do papel civilizatório dos africanos escravizados no Brasil. Segundo Costa e Silva (2007), a época da mineração no Brasil só foi possível devido aos conhecimentos milenares dos africanos das técnicas de metalurgia, fundição de metais e extração de minérios no subsolo. Ressalta ainda que até a revolução industrial os europeus não dominavam com tanta propriedade as técnicas da metalurgia, como faziam algumas sociedades africanas há milhares de anos.

Portanto, do ponto de vista da construção do conhecimento histórico, fica evidente que novas interpretações, com base em pesquisas internacionais recém-publicadas, estão sendo propostas aos sistemas de ensino e principalmente aos docentes, no que tange à interpretação da história da humanidade e da constituição da nacionalidade brasileira. Essas propostas já estão presentes, inclusive, em publicações oficiais do Ministério da Educação e Cultura: "Em todo o continente e em diversas épocas, os povos africanos desenvolveram sistemas de escrita e de altos conhecimentos na astronomia, na matemática, na agricultura, na navegação, na metalurgia, na arquitetura e na engenharia" (NASCIMENTO, E. L., 2006, p. 33).

Em outra publicação do MEC, Educação anti-racista: caminhos abertos pela Lei Federal $n^{\circ}$. 10.639/03, uma coletânea de artigos de diversos estudiosos das questões que envolvem relações raciais e educação e têm como objetivo "planejar, orientar e acompanhar a formulação e a implementação de políticas educacionais, tendo em vista as diversidades de grupos étnico-raciais como as comunidades indígenas, a população afrodescendente dos meios urbano e rural (...)" (BRASIL, 2005, p. 7), afirma-se, em nome do Estado brasileiro, que: "A história da espécie humana se confunde com a própria história da África, onde se originaram, também, as primeiras civilizações do mundo" (MOORE, 2005, p. 136). "O novo empreendimento docente preconizado na Lei 10.639/03 não poderá prescindir da historiografia especificamente produzida por 
africanos, sem ferir gravemente as exigências de rigor e de respeito pela verdade cientificamente elaborada e demonstrada" (Moore, 2005, p. 158).

Reconhece-se hoje que dentre os principais fatores que fizeram com que os povos europeus se voltassem para a África e a transformassem no maior reservatório de mão-de-obra escrava jamais imaginado pelos seres humanos, estava a tradição dos povos africanos de bons agricultores, ferreiros e mineradores. (ANJOS, 2005, p. 171)

Como avaliar o impacto da diferença entre o postulado de Hegel de que a África não possui história, que influenciou gerações de filósofos e historiadores, e essas descrições históricas transformadas em orientações para a formação de professores e o currículo de história?

Nas reflexões da literatura acadêmica, principalmente a partir dos anos 1990, faz-se cada vez mais presente a questão da identidade nacional e da reescrita das histórias do povo negro no Brasil, possibilitando a mobilização do debate sobre a colonialidade do saber, do poder e do ser, pois a história dos negros no Brasil foi invisibilizada na perspectiva da construção de uma nacionalidade em bases eurocêntricas.

Perguntamo-nos: será que o resgate dessas histórias, numa perspectiva de políticas públicas de reconhecimento da diferença colonial - isto é, história da África como elemento condicionador na formação da nação brasileira e as propostas oficiais de reparações -, pode mobilizar um projeto de emancipação epistêmica, na perspectiva de produção de conhecimentos "outros"?

Essas perspectivas se apresentam como possibilidades, já que o denominado giro epistêmico (TORRES, 2007) é um processo em disputa que se desenvolve em diferentes espaços, tanto do âmbito estatal quanto no da academia e dos movimentos sociais.

Nesse sentido, a proposta de uma pedagogia decolonial e de interculturalidade crítica requer a superação tanto de padrões epistemológicos hegemônicos no seio da intelectualidade brasileira quanto a afirmação de novos espaços de enunciação epistêmica nos movimentos sociais.

No entanto, entendemos que, apesar do grande avanço das discussões e dos debates públicos da questão racial negra no Brasil, em torno do resgate da ancestralidade africana, da reparação, das ações afirmativas, etc., para a grande maioria dos afrodescendentes no Brasil ainda está muito presente o mito da democracia racial, que postula a miscigenação 
como uma ordem harmoniosa nas relações raciais brasileiras e estabelece, silenciosamente, um padrão branco de identidade e a necessidade de se ter referenciais eurocêntricos para o reconhecimento social e cultural.

Segundo Munanga (1999), a situação do negro é aquela de refém de um sonho de embranquecimento, de um desejo de fazer aquele passing em direção à cultura branca. Para esse autor, o negro teve sua identidade (referindo-se às suas raízes africanas) impedida de se manifestar. A pressão psicológica sobre ele se estabelece no momento em que toma consciência de que sua invisibilidade aumenta em razão da cor de sua pele, da mais clara à mais escura.

Portanto, além de uma luta decolonial de poder e de saber, para os afrodescendentes a colonialidade do ser é fator relevante nas disputas epistêmicas no campo educacional. Nesse sentido, a partir do pensamento de Catherine Walsh (2006), é possível afirmar que as disputas em torno da Lei 10.639/03 no campo educacional além de apresentarem caráter epistemológico e político, também se caracterizam como um "projeto de existência e de vida".

\section{Concluindo}

A partir da análise realizada, concluímos afirmando que os referenciais presentes na nova legislação possibilitam a abertura a uma crítica decolonial, na medida em que expõem a colonialidade do saber e, ao mesmo tempo, propiciam a explicitação da colonialidade do ser, ou seja, possibilitam a mobilização em torno das questões veladas do racismo presente nas práticas sociais e educacionais no nosso país.

Outro aspecto que pôde ser evidenciado é o fato de pôr em discussão, nos sistemas de ensino e no espaço acadêmico, a questão do racismo epistêmico, ou seja, a operação teórica que privilegiou a afirmação dos conhecimentos produzidos pelo ocidente como os únicos legítimos e com capacidade de acesso à universalidade e à verdade.

O racismo epistêmico considera os conhecimentos nãoocidentais como inferiores. No entanto, atualmente já não é possível negar a existência de histórias e epistêmes fora dos marcos conceituais e historiográficos do ocidente. Almejar desenvolver uma reflexão sobre o ensino de história e suas bases epistemológicas a partir da perspectiva 
"outra" proposta pelo grupo "Modernidade/Colonialidade" requer operar uma mudança de paradigma como precondição para o reexame da interpretação da história brasileira. Essa mudança de paradigma implica também a construção de uma base epistemológica "outra" para se pensar os currículos propostos pela nova legislação, ou seja, novos espaços epistemológicos, interculturais, críticos e uma pedagogia decolonial.

Por fim, podemos considerar que a lei $10.639 / 03$ pode criar condições, dependendo das perspectivas adotadas pelos sujeitos envolvidos, para o estabelecimento, no contexto educacional brasileiro, de conflitos, confrontos e negociações epistêmicas, pondo em evidência a diferença através do pensamento crítico de fronteira, como fundamentado por Walter Mignolo, pois essa legislação permite a visibilidade de outras lógicas históricas, diferentes da lógica dominante eurocêntrica, além de pôr em debate a descolonização epistêmica.

\section{Referências}

ANJOS, Rafael Sanzio Araújo dos. A África, a educação brasileira e a geografia. In: BRASIL

MEC/SECAD. Educação anti-racista: caminhos abertos pela Lei Federal n ${ }^{\circ}$ 10.639/03. Brasília: MEC/SECAD, 2005. p. 167-184.

BHABHA, Homi. O local da cultura. Belo Horizonte: Editora UFMG, 1999.

BRASIL. Parecer 03/2004 do Conselho Pleno do Conselho Nacional de educaşão. Brasília: MEC, 2004a.

BRASIL. Diretrizes Curriculares Nacionais para a Educação das Relações Étnico-Raciais e para o Ensino de História e Cultura Afro-Brasileira e Africana. Brasília: MEC, 2004b.

BRASIL. Educaşão anti-racista: caminhos abertos pela Lei Federal n. 10.639/03. Brasília: MEC/SECAD, 2005.

CASTRO-GÓMEZ, Santiago. Ciencias sociales, violencia epistémica y el problema de la invención del otro. In: LANDER, E. (Org.) La colonialidad del saber: eurocentrismo y ciencias sociales. Perspectivas Latinoamericanas. Buenos Aires: Clacso, 2005. p. 189-186. COSTA E SILVA, Alberto da. Como os africanos civilizaram o Brasil. In: "Vozes da Africa", Biblioteca Entrelivros. São Paulo: Duetto Editorial, edição especial n. 6, p. 6469, mar. 2007.

ESCOBAR, Arturo. Mundos y conocimientos de otro modo. Disponível em: $<$ http://www.decoloniality.net/files/escobar-tabula-rasa.pdf $>$. Acessado em 15 de dezembro de 2008.

FANON, Frantz. Peles negras, máscaras brancas. Rio de Janeiro: Fator, 1983.

FANON, Frantz. Los condenados de la tierra. México: Fondo de Cultura Económica, 2003. GROSFOGUEL, Ramon. Dilemas dos estudos étnicos norte-americanos: multiculturalismo identitário, colonização disciplinar e epistemologias decoloniais. In: Ciência e cultura. São Paulo: v. 59, n. 2 , p. $32-35,2007$. 
HALL, Stuart. Identidades culturais na pós-modernidade. Rio de Janeiro: DP\&A, 1997.

MALDONADO-TORRES, Nelson. Sobre la colonialidad del ser: contribuciones al desarrollo de un concepto. In: CASTRO-GÓMEZ, S.; GROSFOGUEL, R. (Orgs.) El giro decolonial. Reflexiones para una diversidad epistémica más allá del capitalismo global. Bogotá: Universidad Javeriana-Instituto Pensar, Universidad Central-IESCO, Siglo del Hombre Editores, 2007. p. 127-167.

MIGNOLO, Walter. Histórias Globais/projetos Locais. Colonialidade, saberes subalternos e pensamento liminar. Belo Horizonte: Editora UFMG, 2003.

MIGNOLO, Walter. A colonialidade de cabo a rabo: o hemisfério ocidental no horizonte conceitual da modernidade. In: LANDER, E. (Org.). A colonialidade do saber: eurocentrismo e ciências sociais. Perspectivas latino-americanas. Buenos Aires: Clacso, 2005. p. 71-103.

MOORE, Carlos Wedderburn. Novas bases para o ensino da história da África no Brasil. Brasília: In: BRASIL MEC/SECAD Educação anti-racista: caminhos abertos pela Lei Federal n. 10.639/03. Brasília: MEC/SECAD, 2005. p. 133-166.

MOORE, Carlos Wedderburn. O racismo através da história: da antiguidade à modernidade, 2007. Disponível em:

<http://www.ipeafro.org.br/10_afro_em_foco/Moore_Racismo_atraves_da_historia.p df $>$. Acessado em 8 de dezembro de 2008)

MUNANGA, Kabengele. Rediscutindo a mestiçagem no Brasil. Petrópolis: Vozes, 1999.

NASCIMENTO, Elisa Larkin Introdução à História da África. In: MEC. Educação, Africanidades Brasil. Brasília: MEC, 2006. p. 33-51.

OLIVEIRA, Luiz Fernandes de. Concepções docentes sobre as relações étnico-raciais em educação e a lei 10.639. In: Anais da 30ª Reunião da Anped. GT: Didática. 2007.

PEREIRA, Amauri Mendes. Três faces do desafio acadêmico à implementação da Lei 10.639/03: a face filosófica, a face teórica e a face epistemológica. In: GONÇALVES, M. A. R. (Org.) Educação, arte e literatura africana de lingua portuguesa. Rio de Janeiro: Quartet, 2007. p. 59-86.

QUIJANO, Aníbal. Colonialidad del poder, eurocentrismo y América Latina. In: LANDER, E. (Org.). La colonialidad del saber: eurocentrismo y ciencias sociales. Perspectivas Latinoamericanas. Buenos Aires: Clacso, 2005. p. 227-277

QUIJANO, Aníbal. Colonialidad del poder y clasificación social. In: CASTROGÓMEZ, S.; GROSFOGUEL, R. (Orgs.). El giro decolonial. Reflexiones para una diversidad epistémica más allá del capitalismo global. Bogotá: Universidad Javeriana-Instituto Pensar, Universidad Central-IESCO, Siglo del Hombre Editores, 2007. p. 93-126.

SAID, Edward. Orientalismo: o Oriente como invenção do Ocidente. São Paulo: Companhia das Letras, 2001.

SILVA JR, Hédio. Do racismo legal ao princípio da ação afirmativa. In: GUIMARÃES, A.; HUNTLEY, L. Tirando a máscara. Ensaios sobre o racismo no Brasil. Rio de Janeiro: Paz e Terra, 2000. p. 359-387.

WALSH, Catherine. La educación Intercultural en la Educación. Peru: Ministerio de Educación. (documento de trabalho), 2001.

WALSH, Catherine. Introducion - (Re) pensamiento crítico y (de) colonialidad. In: WALSH, C. Pensamiento crítico y matriz (de)colonial. Reflexiones latinoamericanas. Quito: Ediciones Abya-yala, 2005. p. 13-35.

WALSH, Catherine. Interculturalidad y colonialidad del poder. Un pensamiento y posi- 
cionamiento 'otro' desde la diferencia colonial'. In: WALSH, C.; LINERA, A. G.; MIGNOLO, W. Interculturalidad, descolonización del estado y del conocimiento. Buenos Aires: Del Signo, 2006. p. 21-70.

WALSH, Catherine. Interculturalidad Crítica/Pedagogia decolonial. In: Memórias del Seminário Internacional "Diversidad, Interculturalidad y Construcción de Ciudad", Bogotá: Universidad Pedagógica Nacional 17-19 de abril de 2007.

\section{Notas}

${ }^{1}$ Este projeto conta com o apoio do CNPq. No seu desenvolvimento, realizamos ampla revisão da bibliografia, produzida a partir de 2000 no continente, sobre educação intercultural, assim como participamos de diferentes seminários, congressos e encontros, entrevistamos professores/as universitários/as e militantes de movimentos sociais e organizações não-governamentais de diversos países.

2 Resolução n. 01 do Conselho Nacional de Educação, aprovada em 17 de junho de 2004.

3 Devemos relativizar um pouco esta afirmação de Castro-Gomez, pois essas áreas de conhecimento não foram totalmente hegemonizadas por uma visão colonialista ou eurocêntrica.

4 É famosa a afirmação de Hegel de que: “A África não é uma parte histórica do mundo. Não tem movimentos, progressos a mostrar, movimentos históricos próprios dela. Quer isto dizer que sua parte setentrional pertence ao mundo europeu ou asiático. Aquilo que entendemos precisamente pela África é o espírito a-histórico, o espírito não desenvolvido, ainda envolto em condições da natureza e que deve ser aqui apresentado apenas como no limiar da história do mundo" (HEGEL, 1999, p. 174).

5 Os autores do grupo "Modernidade/Colonialidade" usam frequentemente expressões como: "pensamento-outro", conhecimento-outro", etc. Neste contexto, a palavra "outro" quer se referir não somente a qualquer perspectiva alternativa, que pode estar inserida em uma lógica de fundo que não é posta em questão. Quer significar uma mudança de ótica, de lógica, de paradigma.

Recebido: 04/02/09

Aprovado: 13/07/09

Contato:

Pontifícia Universidade Católica do Rio de Janeiro

Centro de Teologia e Ciências Humanas

Departamento de Educação

Rua Marques de São Vicente, 225 - Gávea

CEP 22453-900

Rio de Janeiro/RJ 